\title{
THE CONTRIBUTION OF SELF-REFLECTION IN PORTFOLIO TOWARD STUDENTS' WRITING SKILLS
}

\author{
Tri Setyaningsih; Nurhandayani Supraptiningsih \\ Universitas of Muhammadiyah Prof. Dr. HAMKA \\ tri_setyaningsih@uhamka.ac.id; nurhandayani@uhamka.ac.id
}

\begin{abstract}
Writing is considered to be a sequence of complicated process in which the students need to organize their ideas and develop them into a systematic order. Due to its complexity process, students often find problems in writing, such as idea organization, sentence arrangements, punctuation, and capitalization. Consequently, this study examined the essay writing class students of the undergraduate program to find out whether or not self-reflection in portfolio gives contribution in improving their writing skills. A questionnaire, observational field notes, and document of students' self-reflections were used to collect data about the students' awareness about self-refection, portfolio and writing based on their perspectives. The findings reveal that the self-reflection in portfolio indeed has given contribution toward students' writing through a set of guided questions so that the students become more aware about their strengths and weaknesses in every draft of their writing. Knowing those things will eventually help students to produce better writing on their own that lead them to be autonomous learners.
\end{abstract}

Keywords: writing, portfolio, self-reflection

\section{INTRODUCTION}

In English as a foreign language (EFL) context, it is obvious that speaking and writing are the most difficult skills to master for the students and to teach as well as to assess for the teacher. Harmer (2008) states that writing skill is mostly seen through two major things which are the process and the product. Furthermore, Oshima (1999) illustrates writing as a process of pre- writing, planning (outlining), and writing as well as revising drafts in order to produce a good writing product.

Having done the pre-observation, the writer found out that it is difficult to fulfill the needs of better assessment for the student's writing; whereas, the students themselves also experienced some difficulties in writing class that are mainly related to the idea organization, coherence, sentence problems, punctuation, capitalization, and time management. In this case, Snavely and Wright (2003), Clark (2008) and Caner (2010) suggested to use portfolio assessment as one alternative assessment procedure which represents an ongoing process that enables teachers to assess their students' writing performances (a collection of students' paper) that will be graded or assessed at the end of the course. 
Moreover, Hamp-Lyons \& Condon (2000), Brown (2004), Chang (2008) and Amanto (2010) revealed that self-reflection is an important part of portfolio that helps students review their learning experiences and promote better learning which eventually leads them to be autonomous learners. In addition, there is also a systematic step of selfreflection which is being elaborated by Hegarty (2011). It is called three-step reflective framework which consists of (1) noticing and describing the experience; (2) Analysing the experience and; (3) Taking an action.

On the contrary, Elbow \& Belanoff (1994), Arter \& Spandel (2005) revealed that there is a danger of using portfolio due to its function as a large-scale assessment in representing students' work, progress, and achievement. To respond this matter, teacher should have some considerations in using the appropriate scoring pattern in order to assess students' writing. Wollcot (1998), Weigle (2002) and Wiliams (2003) proposed a holistic scoring as a problem solvent in which it covers a set of specific criteria related to the general quality of a respondent, called a rubric.

In addition, some studies have been conducted in order to validate some findings related to the above issues. A qualitative study conducted by Aydin (2010) evaluates portfolio in EFL learning. It has been verified that portfolio brings effect to the improvement of vocabulary, grammar, reading and research skills, organization of paragraphs and composition, punctuation, capitalization, and other problems found in students' writing. Another study demonstrated by Jensen (2011) who has proven that self-regulation and self-reflection through e-portfolio has successfully help the students to increase the length of their reflection statements written as well as the depth of thinking shown in their statements. Moreover, a study was also conducted by Hawkes (2016) who successfully applied task portfolios for assessment in oral communication courses. He claimed that the participants responded positively to the portfolio assessment, and they stated that the element of pressure involved helped them improve their task performances.

Having given those previous studies above, it can be seen that there are relationships among self-reflection, portfolio, and writing skill. However, there has not been an investigation about the contribution of self-reflection in printed document portfolios to improve students' writing skill, especially in essay writing. Therefore, the writer would like to investigate the contribution of self-reflection in portfolio to improve students' writing skill independently or autonomously as well as to provide herself with better scoring pattern of students' writing in portfolio.

\section{METHOD}

It is a descriptive qualitative study that took place at a private university in Jakarta, mainly focusing on the fifth semester students of essay writing class. There were 12 participants in this research; however, due to the limitation of time, the writer only further investigated five participants whom were selected based on their previous achievement in paragraph writing class; two participants who got lower scores, one participant who got middle scores, and the other two who got higher scores. The participants had to organize four essays; chronological order, logical division of ideas, cause effect, and comparison 
contrast. However, the writer only focused on investigating one writing project which was logical division of ideas. Furthermore, there are some procedures organized in this research through twelve meetings in the classroom, and each meeting was conducted around 100 minutes.

In addition, the data were collected through observational field notes, questionnaire, and document of the participants' self-reflection. The observational field notes covered general opinion during the twelve meetings in the classroom. The documents of students' self-reflection were gathered every time the students had done a process in writing. Also the questionnaire was delivered to the students at the end of the meeting. Furthermore, the writer applied two kinds of analysis; (1) the qualitative data analysis that was validated by theory of triangulation and (2) the self-reflection analysis that illustrated Three-Step Reflective Framework, which was promoted by

Hegarty (2011).

\section{FINDINGS AND DISCUSSION}

The findings were validated through the data triangulation: questionnaire, observational field notes, and documents (self-reflection). Each problem was being analyzed thoroughly and systematically in order to find out things as follows:

\section{How the students organize the ideas in their writing through portfolio}

The first problem to be analyzed is about how students organize ideas in their writing through portfolio. The findings are described through parts of the questionnaire dealing with participants' point of view about writing and portfolio. It was found out that the participant's understanding about writing subject is divided into parts: $50 \%$ think that it is a complicated and complex process; and the other $50 \%$ think that it is a sequence process of developing ideas.

This is in balance with their perspective toward themselves as writers: six participants agree that they are quite-good writers since they are still in the learning process of writing through a systematic and organized process; however, the other six participants claim themselves as bad writers, for they often face difficulties in writing dealing with idea organization and sentence arrangement even though some of them got A on grammar lessons.

Despite their perception above, it is clarified that aside from the academic assignment: $16 \%$ of the participants only write when they are in the mood; $42 \%$ write in their diary or blog when they experienced good or bad things; and the other $42 \%$ said that they never write unless they have assignment. In fact, there are 11 participants who agree that their previous writing classes help them to write through sequence of process, yet there is one participant who disagrees since she claims that she only learned grammar in sentence writing instead of learning sentence arrangement and/or writing practice.

Moreover, looking back to their previous paragraph writing class, $92 \%$ of the participants believe that paragraph is a group of sentences which has one main topic and supporting sentences such as examples or reasons, and the other $8 \%$ remember paragraph as a group of sentences which begins with a capital letter and ends with a period. In addition, there 
are seven participants who define essay as a group of paragraphs which consists of introduction, body (some supporting sentences), and concluding part; also, five participants who recognize essay as a group of paragraphs which has one thesis statement.

In line with their good comprehension about paragraph and essay, there is only one participant who directly searches for information needed in her essay when the teacher asks her to make an essay; whereas, the other eleven participants always use particular process: Narrowing a Topic (NT), Brainstorming (B), and Outlining (O) process whenever the teacher ask them to make essay.

Furthermore, the participants have various ways to develop their ideas through portfolio as it can be seen through figure 1 below. There are $42 \%$ who develop ideas through previous drafts of NT, B, and O process; there are 33\% who apply portfolio attributes like Self-Reflection (SR), Peer Feedback (PF), and Student-Teacher Conference (STC) form; and there are $25 \%$ who directly focus on the finding new sources through internet without paying attention to the process.

Figure 1: The Questionnaire Result: How the students organize the ideas in their writing through portfolio

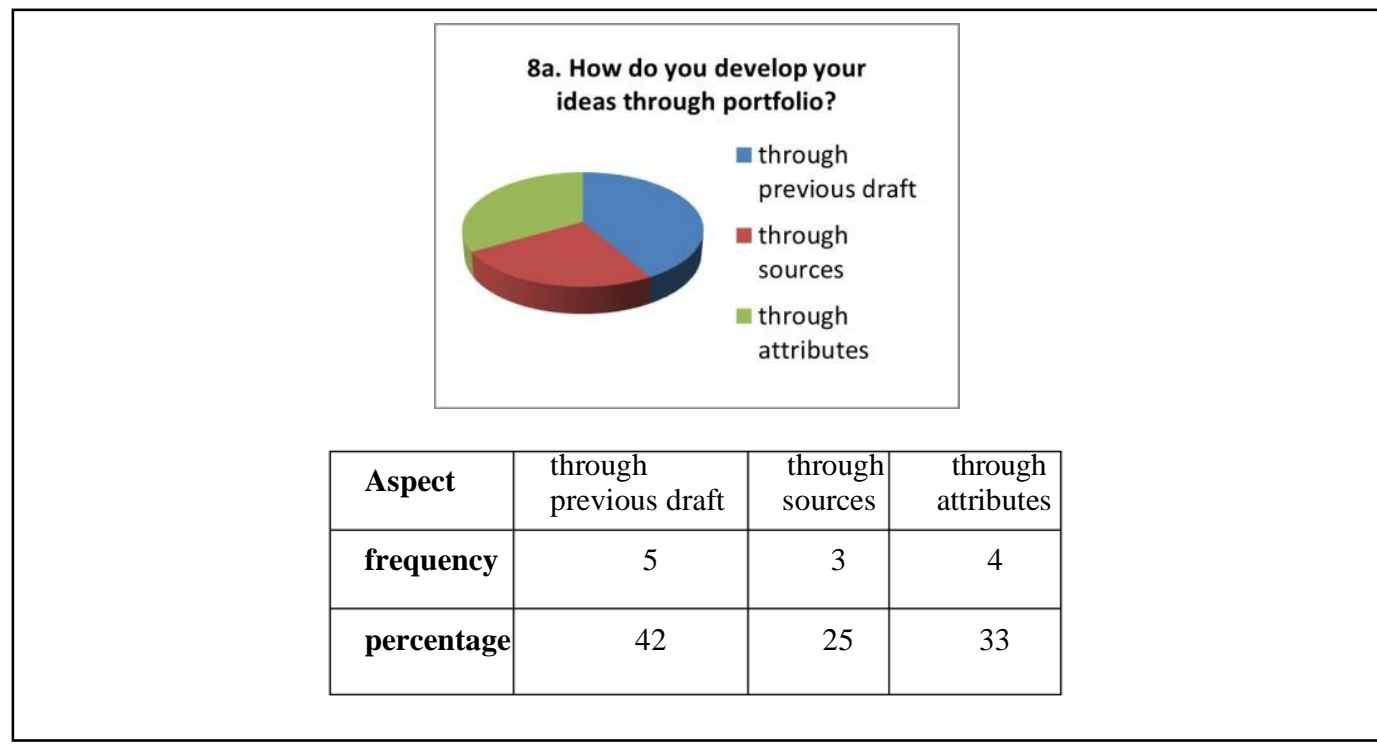

In addition, the finding in which the participants usually organize ideas in writing through previous drafts of NT, B, and $\mathrm{O}$ process is also proven from observational field notes $(O F)$. Through OF (M.2), it is found out that the participants were focusing on the discussion of $\mathrm{NT}, \mathrm{B}$, and $\mathrm{O}$ process in writing which were being shown by using projector. They were also busy developing their ideas of Logical Division of Ideas (LDoI) essay through NT, B, and O process from M.2 until M.7.

In this case, the participant's speed in doing those processes was different one to another. It only took Student 03 (S.03) and S.04 one draft of NT so that they started to do $\mathrm{B}$ and O process for three-time drafting. However, it took S.09 to have two drafts of NT since she had sentence problem in her specific topic. Hence, S.06 had to go through five attempts of NT, and S.08 had nine drafts of NT. They had some attempts to do NT process because the ideas they had submitted were similar to their friends' ideas. 
Likewise, how students organize ideas in their writing through portfolio is clearly described by S.06 in her self reflection (SR) as follows:

I made the narrowing down, brainstorming, and outlining the ideas before I elaborated them into the essay. In narrowing down, I limited "culture" as the general topic into "four kinds of traditional musical instrument from West Java" as my specific topic. In brainstorming, I detailed them in different page, one page for one instrument. In outlining, I tried to write the obvious ideas about the specific topic I have.

\section{How self-reflection help students to solve sentence problems}

Furthermore, the second problem of this research is concerned on how self-reflection (SR) helps students to solve sentence problems. The findings are explored in details from the questionnaire, part $\mathrm{B}$, which is mainly focusing on the writing and reflecting. Regarding this matter, the participants find benefits in using portfolio to their writing: $17 \%$ of the participant have been benefited from portfolio as file saving which can compile all of their writing process, $50 \%$ believe that they can take advantage of portfolio as reflective display of writing which can help them to find their strength and weakness in writing through SR, PF, STC form. Similarly, 33\% of the participants think that they have been benefited by portfolio since they can both use it as file saving and reflective display of writing.

The participants' perspectives in seeing portfolio as a reflective display of writing happened because $33 \%$ of the participants are in common for having found difficulties in each organizing idea, arranging sentences, and both. As a result, they have different point of view about whether or not portfolio can help them in handling sentence problems. However, there are two participants who do not really agree, for they believe that it is not the portfolio which helps them, it is the portfolio contents that help them in reviewing their mistakes. On the contrary, there are ten participants who admit that portfolio can help them in handling sentence problems. They always use the content and attributes of portfolio, like the previous drafts and SR form which has guided questions to help them self-reflecting what problems they have in their essay so that they can solve those problems.

Figure 2: How SR helps students in handling sentence problem

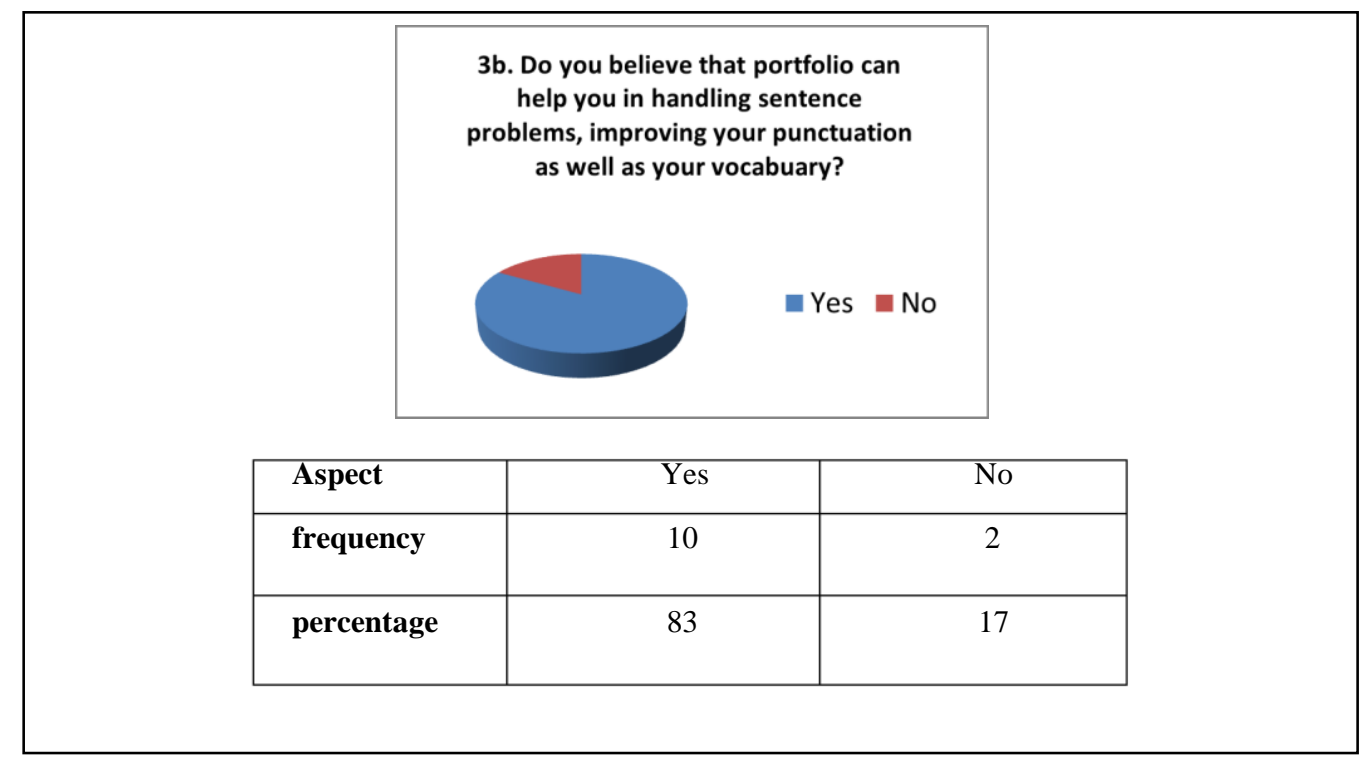


In this case, the students' track in which they were using SR along the writing process is captured in Observational Field Notes (OF) starting from M.5 to M.12. It means that the students understand and apply this SR form since all of them have managed their SR systematically and in order in their portfolio folder.

Moreover, the result that self-reflection can help students to handle sentence problems through its guided questions as being described above is also confirmed by S.05 below.

During the writing process, I have difficulty in sentence arrangement. Since portfolio consists of self-reflection, it helps me knowing what problems in my essay task, and then I must try to solve them. I know and reflect the problems during the writing process through guided questions provided in portfolio.

\section{How portfolio helps teacher in assessing students' writing}

This third problem is related to the questionnaire, part $\mathrm{C}$, which explores about the students' perspective toward portfolio. It can be seen that the students have different and varied opinion about portfolio keeping in essay writing class: $17 \%$ of the participant think that portfolio keeping is helping them to arrange their files systematically and wellorganized. Another 17\% agree that it is both helping and entertaining since they are allowed to create and design the portfolio folder based on their preference. However, there is $8 \%$ who claim that portfolio keeping is tiring, for they need to go through some systematic process of writing. Likewise, there are $25 \%$ of the participants who believe that portfolio keeping is both helping and tiring due to similar reasons mentioned previously. The other 33\% states that portfolio keeping is helping, entertaining, and tiring as well.

Furthermore, most of the students also acknowledge that there are major differences after using portfolio; $92 \%$ of the participants say that their writing process are safe and well organized in the folder so that they realize that their writing has a plot. In fact, they start to learn on how to reflect their writing process as well. On the other hand, there is $8 \%$ who think that there is no difference before or after using portfolio. The students' recognition to the use of portfolio in their essay writing class had brought them to have better understanding on how to use portfolio, especially related to the attributes of portfolio itself.

In this case, the students know exactly what the portfolio attributes are. There are ten students who are able to mention the portfolio attributes which are: cover page, personal introduction, table of content, samples, sources, essay writing process: NT, B, O, drafting process; and the other attributes, like: SR, PF, STC form, and scoring rubric. There are also two students who failed to remember about the SR and scoring rubric. In addition having been through the systematic process of writing, all of the students preferred to be assessed by using portfolio instead of using paper-pencil test. It means that the students noticed about the importance of portfolio which includes the existence of selfreflection and scoring rubric in writing class. 
Figure 3: How portfolio helps teacher in assessing students' writing

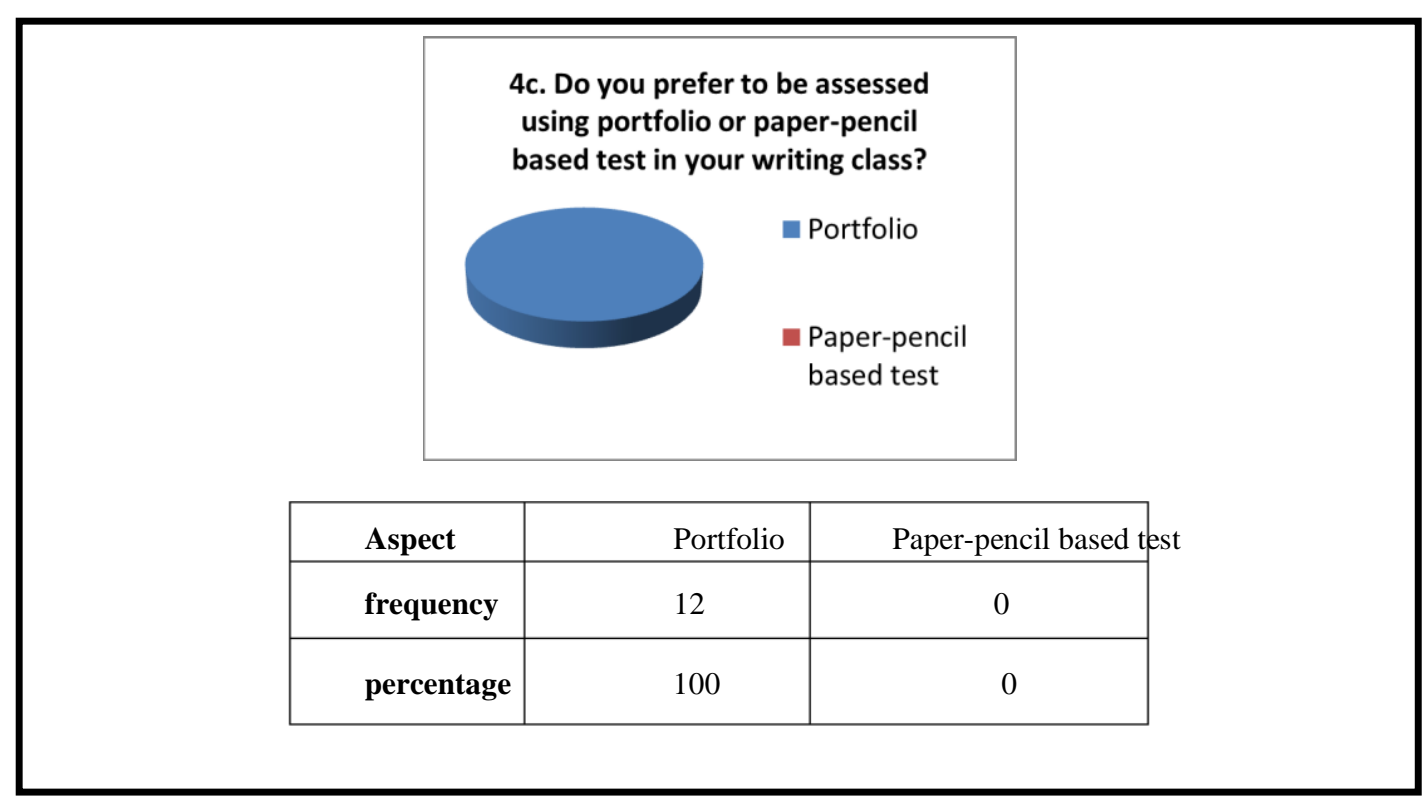

In fact, the discussion of portfolio scoring rubric has been mentioned previously in the beginning of the meeting as it is stated in the OF M.3. The teacher introduced and explained about the importance of portfolio and the also the attributes including SR and scoring rubric to the students. It was when the teacher brought the samples of essay and attributes as well as the scoring rubric to be shown to the students.

At last, the following statement is taken from S.06 SR which supports the previous idea that the teacher and the students had discussed about portfolio scoring rubric in the early meeting.

My portfolio consists many important things: table of content, the models of essay, the whole process in writing (NT, B, O, drafting), SR, WPTS, PF, STC, sources, correction symbols, list of transition signals, example of provoking title, and scoring rubric.

\section{CONCLUSIONS}

Having done the analysis of those data above, the writer has these three main findings of this research: (a) the students can develop and organize their ideas in portfolio through their 
previous drafts of narrowing a topic, brainstorming, and outlining process; (b) students can handle their difficulties in sentence problem by using guided questions in self-reflection; (c) teacher can assess students' writing through portfolio scoring rubric which involves aspects of students' process and progress in writing class.

The findings above have proven that the self-reflection in portfolio indeed has given significant contribution toward students' writing through a set of guided questions so that the students become more aware about their strengths and weaknesses in every draft of their writing. It can be concluded that teaching writing is not just a matter of teaching students to write better; indeed, it is a matter of how teacher helps students in making writing and reading as their habit. All in all, it is about how to teach them to be autonomous learners eventually.

\section{REFERENCES}

Amanto, P.A.R. (2010). Making It Happen. New York: Pearson Education, Inc.

Arter, J.A., and Spandel, V. (2005). Using portfolios of student work in instruction and assessment.<http://onlinelibrary.wiley.com/doi/10.1111/j.17453992.1992.tb00230.x/abstract $>$

Aydin, Selami. (2010). A Qualitative research on portfoliokeeping in English as a foreign language writing. The Qualitative Report, 15, 3.

Brown, H.D. (2004). Language Assessment: Principles and Classroom Practices. New York: Pearson Education, Inc.

Caner, M. (2010). Students views on using portfolio assessment in EFL writing course. Anadolu University Journal of Social Sciences, 10, 1.

Creswell, J.W. (2011). Educational Research: Planning, Conducting, and Evaluating Quantitative and Qualitative Research. Fourth Edition. Boston: Pearson Education Inc.

Chang, C.C. (2008). Enhancing self-perceived effects using web-based portfolio assessment. Computers in Human Behavior, 24, 3.

Clark, I.L. (2008). Concepts in Composition: Theory and Practice in the Teaching of Writing. New Jersey: Taylor \& Francis e-Library.

Elbow, B. (1994). New Direction in Portfolio Assessment: Reflective Practice, Critical Theory, and Large-Scale Scoring. Portsmouth: Boynton/Cook Publishers, Inc.

Hamp-Lyons, L., and Condon, W. (2000). Assessing the Portfolio. USA: Hampton Press, Inc.

Harmer, Jeremy. (2008). How to Teach Writing. England: Pearson Education Limited.

Hawkes, Martin. (2016). Using Task Portfolios for Assessment in Oral Communication Courses. Asian EFL Journal, 90(2), 28-53. 
Hegarty, B. (2011). Is reflective writing an enigma? Can preparing evidence for an electronic portfolio develop skills for reflective practice? <http://www.leishmanassociates.com.au/ascilite2011/downloads/papers/Hegarty-full.pdf.>

Jenson, Jill D. (2011). Promoting self-regulation and critical reflection through writing students' use of electronic portfolio. International Journal of ePortfolio, 1, 1.

Moon, J.A. (1999). Learning Journals, Kogan Page.

Oshima, A. (1999). Writing Academic English. England: Longman.

Snavely, L.L., and Wright, C.A. (2003). Research portfolio use in undergraduate honors education: Assessment tool and model for future work. The Journal of Academic Librarianship, 29, 5.

Weigle, S.C. (2002). Assessing Writing. UK: Cambridge University Press.

Williams, J.D. (2003). Preparing to Teach Writing: Research, Theory, and Practice. New Jersey: Lawrence Erlbaum Associates, Inc.

Wolcott, W. (1998). An Overview of Writing Assessment: Theory, Research, and Practice. Urbana, IL: National Council of Teachers of English. 